\title{
The Language Awareness of the L2 Teacher: Its Impact Upon Pedagogical Practice
}

\section{Stephen Andrews}

Department of Curriculum Studies, Pokfulam Road, University of Hong Kong, Hong Kong

The paper sets out to examine the ways in which a teacher's language awareness affects their pedagogical practice. It begins by considering the relationship between teacher language awareness and pedagogical content knowledge (PCK), arguing that there is something unique about the PCK of the $L 2$ teacher, because the content and medium of L2 instruction are so closely interrelated. A model is proposed, in which the L2 teacher's language awareness (TLA) is seen as a sub-component of PCK, forming a bridge between knowledge of subject matter and communicative language ability. The paper then considers the role in the instructed learning setting of the L2 teacher's TLA, with specific reference to grammar. Following Andrews 1999a, the impact of TLA is examined through its interaction with the three main sources of language input for learners: materials, other learners, and the teacher. The paper then offers an overview of the effects of TLA on pedagogical practice, and identifies various potential influences on the operation of any teacher's metalinguistic awareness. The paper concludes with discussion and illustration of one of these potentially influential factors, the teacher's engagement with content-related issues, drawing on data from an in-depth study of 17 L2 teachers (Andrews, 1999b).

\section{Introduction}

The aim of the present paper is to examine the language awareness of the L2 teacher (referred to hereafter as TLA), and to consider the impact of TLA on pedagogical practice. The focus of the paper is on L2 teaching and learning, with specific reference to TLA as it relates to grammar. However, many of the issues raised may be equally relevant to L1 (or L3) teaching, and the TLA construct is seen as applying in principle to the full range of a teacher's language knowledge and awareness, not just to grammar.

The paper seeks to address the following questions:

- What is TLA?

- What is the relationship between TLA and 'input'?

- What is the impact of TLA on pedagogical practice?

- What factors influence the impact of TLA on pedagogical practice?

In the final section, the paper draws on data from an empirical study (Andrews, 1999b) to examine the impact of one potentially influential factor: the extent to which a teacher actually 'engages' with content-related issues in his or her teaching.

\section{What is TLA?}

In relation to L2 education, Thornbury (1997) offers the following definition of 
the language awareness of teachers: 'the knowledge that teachers have of the underlying systems of the language that enables them to teach effectively' (Thornbury, 1997: x). According to such a view, TLA is essentially concerned with subject-matter knowledge and its impact upon teaching.

The following comments by a Hong Kong secondary school teacher of English clearly illustrate the central role of subject-matter knowledge in any teacher's language awareness. They also indicate the sort of problems that can arise when teacher subject-matter knowledge is lacking. The comments, and the rest of the data referred to in this chapter, are taken from an in-depth study of the language awareness (relating to grammar) of a group of Hong Kong secondary school teachers of English (Andrews, 1999b). The interviewee, Rose, was describing the difficulties she experienced in a recent lesson teaching passive voice, and acknowledging that they stem from limitations in her own explicit knowledge of grammar:

It's easy if you ask them to rewrite the sentences, because they find it easy to follow. However ... they just don't know when we are supposed to use passive voice and when we are supposed to use active voice. And one of the students even asked me 'Miss Wong, why do we have to use passive voice in our daily life?' and I find this question difficult to answer, ha, and I 'Oh, I'll tell you next time' ... and then I asked my colleagues 'Why do we use and teach passive voice?' and no one can give me the correct answer. And then I go home and think about it. But even now I really don't know how to handle that student's questions. I finish the worksheets with them and they know how to rewrite the sentences. But I don't know how to explain to them. (Andrews, 1999a: 169, 1999b: 178)

From what Rose says, she and her students appear to have no problems dealing with mechanical exercises transforming active sentences to passive and vice versa. However, once attention switches to the meaning of passive voice, and the reasons for selecting active or passive, Rose admits that she is unable to resolve her students' difficulties. The implied reason is that she lacks the relevant 'knowledge ... of the underlying systems of the language'.

Rose's comments are evidence that subject-matter knowledge is an important, indeed necessary, part of TLA. However, when we look at examples of how teachers handle grammar-related issues in the classroom itself, it becomes apparent that the relationship between subject-matter knowledge and classroom teaching is very complex, and that subject-matter knowledge alone is not sufficient to ensure the effective application of TLA in pedagogical practice. Take, for instance, the case of another Hong Kong secondary school teacher: Karen. In the course of her Form $4^{1}$ lesson on question-formation, Karen attempted to help her students understand some of the complexities of meaning associated with the modal will in the question: Will you come at 8am? Karen gave her students the following explanation:

For this word will we have two kinds of meaning. Number 1 you can say that it's about future tense ... maybe it's now 4 a.m., and then Will you come at $8 \mathrm{am}$ ? Future tense ... Or another one may be ... Do you know that traditionally if I say I shall go/I will go, they are different? Can you remember? I 
shall go is about future, I shall go future tense. And then I will go maybe the underlying meaning is like this I must go/I have to go. And then for this one again it's the same Will you come at 8 am? Maybe it's about the future and secondly you can say that Do you have to come? Or Will you really come? Because I hope that you can come. And then Yes, I will come, I must come, I will come ... something like that. (Andrews, 1999b: 180)

From the learners' perspective, there seem to be a number of potential problems with Karen's explanation. However, the inadequacies of Karen's explanation are much less obviously the result of a gap in subject-matter knowledge than the problems reported by Rose. Indeed, Karen, over a series of observed lessons, reveals no major weaknesses in subject-matter knowledge. There are, though, a number of similar instances in those lessons where Karen's output in the classroom seems to be inadequately monitored, where she tends to say too much about grammar-related issues with arguably insufficient reflection upon the intelligibility or usefulness of what she is saying. In other words, it appears that Karen is not really thinking about the language content from the viewpoint of the learners, taking into account their potential difficulties. Analysing language from the learner/learning perspective is clearly an important aspect of TLA. Karen's problems in this regard offer confirmation of the point made earlier, that the successful application of TLA in practice does not depend solely on a sound language systems knowledge base.

The extract from Karen's lesson suggests that there are a number of elements contributing to the complexity of TLA. Of particular significance is the relationship between a teacher's subject-matter knowledge and her language proficiency, or 'communicative language ability' (CLA) in Bachman's terms. Bachman's model of CLA consists of 'both knowledge, or competence, and the capacity for implementing, or executing that competence in appropriate, contextualised communicative language use' (Bachman, 1990: 84). It subsumes language competence, strategic competence and psychophysiological mechanisms.

The closeness of the link between subject-matter knowledge and CLA becomes clear if one stops to consider the nature of a teacher's content-related activity both pre-lesson and in-lesson. In preparing for lessons with a grammar focus, for example, the teacher's reflections on lesson content are likely to encompass both her explicit knowledge of the relevant grammar rules and her own communicative use of the grammar item. Then, once the teacher is in the classroom, anything she says about grammar during the lesson will not only draw on her subject-matter knowledge, but will also be mediated through her CLA. ${ }^{2}$ From this, then, it seems reasonable to argue that much of the complexity of TLA derives from the uniqueness of the situation in language teaching, where content and medium of instruction are inextricably intertwined.

Based on all the above, it would seem that any model of TLA would need to take account of the following:

(1) The language knowledge/awareness of the teacher embraces both knowledge of subject matter and CLA, since it involves reflections on both and entails the mediation of the former through the latter.

(2) The language knowledge/awareness required by the teacher of a language 
is qualitatively different from that of the educated user of that language. As Andrews 1999a argues, the teacher of a language, like any educated user of that language, undoubtedly needs levels of implicit and explicit knowledge of grammar which will facilitate effective communication. In the case of the teacher, her effectiveness as a communicator is directly linked to her adequacy as a model for her students. At the same time, however: 'effective L2 teaching requires of the teacher more than just the possession of such knowledge and the ability to draw upon it for communicative purposes. The L2 teacher also needs to reflect upon that knowledge and ability, and upon her knowledge of the underlying systems of the language, in order to ensure that her students receive maximally useful input for learning' (Andrews, 1999a: 163).

(3) The language knowledge/awareness of the teacher is therefore 'metacognitive', i.e. it involves 'cognition about cognition' (Flavell, 1981, quoted by Gombert, 1992: 7). In other words, TLA is not just knowledge of subject matter mediated through a teacher's CLA, but rather, as suggested above, it also involves an extra cognitive dimension of reflections upon both knowledge of subject matter and CLA, which provides a basis for the tasks of planning and teaching. (See, for example, Andrews, 1997, 1999a, 1999b where the term 'teacher metalinguistic awareness' is used to emphasise the importance of this metacognitive dimension.)

There are obvious connections between this conception of TLA and the more generic construct pedagogical content knowledge, or PCK (see, for example, Shulman, 1986 and the collection of papers in Brophy, 1991). Brophy describes PCK as:

a special form of professional understanding that is unique to teachers and combines knowledge of the content to be taught with knowledge of what students know or think they know about this content and knowledge of how this content can be represented to the students through examples, analogies etc. in ways that are most likely to be effective in helping them to attain the intended outcomes of instruction. (Brophy, 1991: xii)

It is clear that many of the wide-ranging concerns of PCK, as defined above, are equally important to TLA. However, it could also be argued that the unqualified application to language teaching of a generic term like PCK overlooks the uniqueness of the process of language teaching, referred to earlier, in which language is taught through language. For this reason, rather than treating TLA as a synonym for the language teacher's PCK, it seems more appropriate to use the term TLA as well as the more generic and all-embracing term in order to emphasise the unique features of the language teacher's pedagogical content knowledge, of which her language awareness may be seen as a major sub-component.

Figure 1, from Andrews (1999b), attempts to reflect the points above, by representing TLA as forming a bridge between language competence/strategic competence (as the major components of CLA) and knowledge of subject matter (as a central part of PCK). As such, TLA can be seen both as a pedagogically 


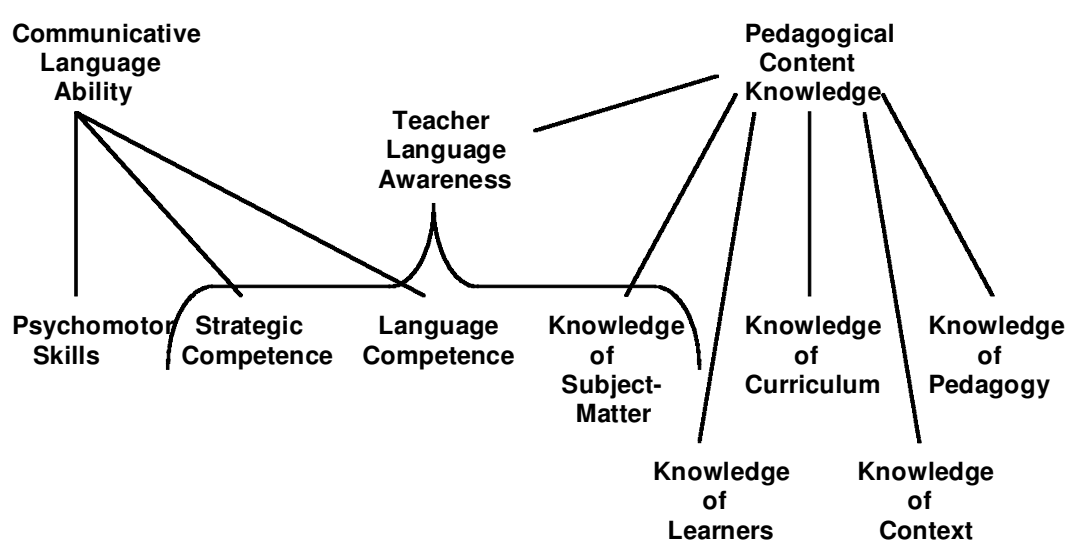

Figure 1 The relationship between teacher language awareness (TLA), communicative language ability (CLA) and pedagogical content knowledge (PCK)

related reflective dimension of CLA, and also as a sub-component of the L2 teacher's PCK, which interacts with the other sub-components.

In this discussion of the nature of TLA it is also worth noting the use of the word 'awareness' in preference to 'knowledge'. This underlines both the dynamism of the construct, a quality implicit in Shulman's own cyclical model of pedagogical reasoning and action (Shulman, 1987), and also the importance of the two dimensions of knowledge: the declarative and procedural dimensions (see, for example, Anderson, 1983). Shulman's construct incorporates a procedural as well as a declarative dimension, as does TLA, with knowledge of subject matter (i.e. the language systems knowledge base) at the core of the declarative dimension of TLA. In the case of teacher language awareness, the dynamism and the bidimensional nature of the construct mean that cognitions and reflections about language are seen in action, interacting with other aspects of communicative language ability, and evolving as a result of that interaction, 'in contrast to a view of teachers' language awareness which sees it simply as declarative KAL related to pedagogy' (Andrews, 1997:149).

\section{TLA and Teacher Behaviour : The Relationship Between TLA and 'Input'}

In recent years, there have been various attempts to characterise how language awareness affects teacher behaviour. Thornbury (1997), for example, lists a number of potential consequences of weakness in the area of language awareness:

a failure on the part of the teacher to anticipate learners' learning problems and a consequent inability to plan lessons that are pitched at the right level; 
an inability to interpret coursebook syllabuses and materials and to adapt these to the specific needs of the learners; an inability to deal satisfactorily with errors, or to field learners' queries; and a general failure to earn the confidence of the learners due to a lack of basic terminology and ability to present new language clearly and efficiently. (Thornbury, 1997: xii)

Other writers (for example, Andrews, 1994; Leech, 1994) have attempted to outline ways in which TLA might ideally reveal itself in pedagogical practice. Leech, for instance, talks of the 'mature communicative knowledge' of grammar required by the teacher. The characteristics of Leech's 'model' teacher of languages are summarised in Andrews, 1999a, but they include being able to analyse the grammatical problems that learners encounter, and evaluate learners' use of grammar against criteria of accuracy and appropriateness, while at the same time understanding and being able to implement the processes of simplification by which overt knowledge of grammar can best be presented to learners at different stages of learning (Leech, 1994: 18)

The characteristics listed by Thornbury and Leech may differ in their perspective. However, what they have in common is a focus on the knowledge, awareness and ability which the teacher brings to the task of dealing with issues relating to 'input': 'the target language samples to which the learner is exposed' (Ellis 1990:96). There seems to be very little consensus among SLA researchers as to how languages are learned or acquired (as illustrated by the range of theoretical perspectives surveyed in Mitchell \& Myles, 1998), and any discussion of these differing viewpoints would be beyond the scope of the present paper. What is clear, however, is that it is a precondition for learning that learners should be exposed to input (see, for example, Brown, 2000:73; Mitchell \& Myles, 1998:14).

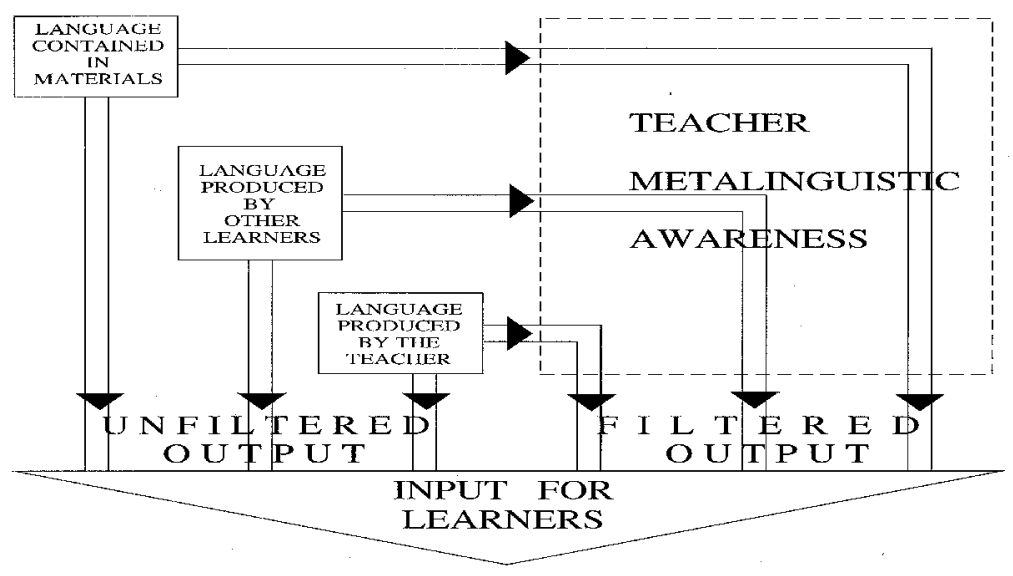

Figure 2 The role of TLA in structuring input for learners 
The model in Figure 2 (Andrews, 1999a: 166, 1999b: 34) uses the 'filter' metaphor to represent the interaction between input and teacher language awareness ('Teacher Metalinguistic Awareness' in the model). According to Figure 2, there are three main sources of input for learners: materials, other learners, and the teacher. As the model suggests, output from each source may reach the learner as input without any teacher mediation (i.e. in 'unfiltered' form). Alternatively, such output may be mediated ('filtered') by the teacher, either before or as it is made available to the learner. The assumption on which the model is based is that the quality of the TLA 'filter' has a potentially crucial effect on the mediation or structuring of input for learners.

\section{The Impact of TLA on Pedagogical Practice}

To obtain an idea of the range of aspects of pedagogical practice upon which TLA might have an impact, the simplest way is to itemise the range of grammar-related tasks which the teacher might perform with the intention of facilitating learning, since each one is potentially affected by the quality of that teacher's language awareness. Some of these tasks are undertaken as part of lesson preparation. Others occur as spontaneous interventions, in response to events in the classroom.

The major pre-lesson task in which TLA plays a part involves analysing the grammatical area from the learner and learning perspective. TLA affects the teacher's ability to identify the key features of the grammar area for learning and to make them salient within the prepared input. It also affects her ability to specify the most appropriate learning objectives, and to select materials and tasks which are most likely to serve those objectives, ensuring that they are appropriate in terms of the learners' age and previous learning, and that they serve the desired learning outcomes.

Within the classroom, TLA has a profound effect upon the teacher's performance of a range of tasks. These tasks include: (1) mediating what is made available to learners as input; (2) making salient the key grammatical features within that input; (3) providing exemplification and clarification, as appropriate; (4) monitoring students' output; (5) monitoring one's own output; (6) helping the students to make useful generalisations based upon the input; and (7) limiting the potential sources of learner confusion in the input; while all the time (8) reflecting on the potential impact of all such mediation on the learners' understanding.

Careful preparation can, to some extent, help the teacher to meet these challenges. However, in the classroom, many of these tasks need to be performed spontaneously and in 'real time'. The effective operation of the procedural dimension of TLA therefore involves a variety of factors: not just vision, perception, sensitivity and reflection, but also alertness and quick thinking, a knowledge-base which can be readily accessed, and a good level of communicative language ability. The experiences of both Karen and Rose (discussed earlier) illustrate the difficulties experienced by many teachers confronted with such demands.

Figure 3 (from Andrews, 1999b) summarises the potential impact of TLA, positive and negative, upon pedagogical practice. The figure distinguishes 


\section{Impact of TLA in the classroom}

\begin{tabular}{|c|c|}
\hline Positive & Negative \\
\hline $\begin{array}{l}\text { Teacher acts as a bridge } \\
\text { between the language content } \\
\text { of the materials and the learners, } \\
\text { making salient the key features } \\
\text { of the grammar area. }\end{array}$ & $\begin{array}{r}\text { Teacher does little or nothing } \\
\text { to act as a bridge/make salient } \\
\text { the key features of the grammar } \\
\text { area (e.g. doesn't go beyond the language } \\
\text { content as presented in the materials). }\end{array}$ \\
\hline $\begin{array}{l}\text { Teacher 'filters' the content } \\
\text { of published materials, and } \\
\text { notices/avoids potential } \\
\text { pitfalls. }\end{array}$ & $\begin{array}{l}\text { Teacher is unwilling/unable to 'filter' } \\
\text { content. As a result, teacher may } \\
\text { overlook or accept misconceptions } \\
\text { and/or inaccuracies in materials. }\end{array}$ \\
\hline $\begin{array}{l}\text { Teacher 'filters' own classroom } \\
\text { output (spoken and written) } \\
\text { to ensure that it is } \\
\text { - structurally accurate } \\
\text { - functionally appropriate } \\
\text { - clearly expressed } \\
\text { - pitched at the learners' level } \\
\text { - } \quad \text { an adequate basis for learner generalisations }\end{array}$ & 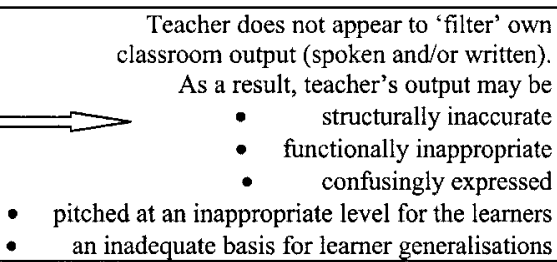 \\
\hline $\begin{array}{l}\text { Teacher 'filters' learner output } \\
\text { (as appropriate in the context of } \\
\text { form-focused activity). Mediation } \\
\text { takes the learners' perspective } \\
\text { into account, and is } \\
\text { - correct, precise and intelligible } \\
\text { - structurally accurate } \\
\text { - functionally appropriate } \\
\text { - pitched at the learners' level } \\
\text { - an adequate basis for learner generalis }\end{array}$ & $\begin{array}{r}\text { Teacher's mediation of learner output in } \\
\text { form-focused activity is inadequate. As a result, } \\
\text { incorrect learner output may be ignored, } \\
\text { the learners' perspective may not be taken into } \\
\text { account, and teacher mediation may be }\end{array}$ \\
\hline $\begin{array}{l}\text { Teacher is able to operate 'filter' } \\
\text { in 'real time', reacting spontaneously } \\
\text { and constructively to issues of language } \\
\text { content as they arise in class. }\end{array}$ & $\begin{array}{c}\text { Teacher has difficulty in operating } \\
\text { 'filter' in 'real time', and in reacting } \\
\text { spontaneously and constructively to issues } \\
\text { of language content as they arise in class. }\end{array}$ \\
\hline $\begin{array}{l}\text { Teacher is able to employ metalanguage } \\
\text { to support learning } \\
\text { - correctly } \\
\text { appropriately }\end{array}$ & 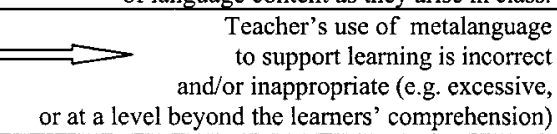 \\
\hline
\end{tabular}

Figure 3 The impact of TLA in the classroom (Source: Andrews, 1999b: 191)

between the positive and negative impacts of TLA, with the descriptors outlining the opposite extremes. However, as the arrows are intended to indicate, each potential impact is in fact a matter of degree.

\section{Factors Influencing the Impact of TLA on Pedagogical Practice}

The preceding discussion has argued that two factors specific to language are central to the operation of the TLA 'filter' described earlier. The first of these is subject-matter knowledge. As Thornbury suggests, this is crucial to the successful application of TLA in pedagogical practice: it is effectively the declarative dimension of TLA. In relation to grammar learning, for instance, the quality of a teacher's thinking, actions and reactions at all stages - in preparation, teaching, and also in post-lesson reflection - is clearly dependent on a sound underlying language systems knowledge base. It is equally evident, however, that explicit 
knowledge of grammar, while a necessary part of a teacher's language awareness, is not sufficient by itself to ensure that that teacher will deal with grammar-related issues in ways which are most conducive to learning.

Communicative language ability is the second language-specific factor central to the application of TLA. It affects not only the quality of the teacher's reflections about language. It also has a direct effect upon the structural accuracy and functional appropriacy of the teacher's mediation of all three potential sources of language input.

These two language-related factors are undoubtedly of great importance in determining the quality of teacher-produced input and the effectiveness of the teacher's mediation of other potential input sources. However, there are other factors - of personality, attitude and context - which also have a powerful influence upon the application of TLA in pedagogical practice (see the discussion in Andrews, 1999b:137-188). For instance, one such key factor is the extent to which the teacher seriously engages with grammar-related issues in the classroom at all. The degree of teacher engagement may be related in part to that teacher's self-confidence, or lack of confidence, in relation to grammar. It may also be affected by the relative importance which the teacher accords to content issues rather than questions of methodology, classroom organisation, and student responsiveness. This will be considered in more detail in the following section.

Assuming that the teacher does engage with specific issues of grammar pedagogy, there are a number of other factors affecting the application of TLA in the classroom. Contextual factors, such as pressure of time and the need to follow a prescribed syllabus, certainly play a significant role (Andrews, 1999b:148-151). Equally important, however, are personality factors such as sensitivity, perception, vision, reflectiveness, and alertness (see, for example Andrews, 1999b: 172-177). Whatever the difficulty in subdividing, categorising and defining affective factors precisely (as discussed, for example, by Brown, 2000: 143), there is little doubt that the affective domain, i.e 'the emotional side of human behaviour' (Brown, 2000) has the potential to impact significantly on TLA in pedagogical practice.

Together these various influences have a powerful effect upon the teacher's willingness to engage with language-related issues, and upon their capacity for 'reflection-on-action' and 'reflection-in-action' (Schon, 1983), as well as on the feasibility of each teacher's personal engagement with and reflection on language-related issues in their teaching. Figure 3 below illustrates these key influences on TLA in pedagogical practice: the procedural dimension of TLA. It should be noted, however, that within each individual teacher, these factors are likely to interact in a variety of ways, with differing consequences. Just as the precise combination of factors may vary from individual to individual, so one should not expect the interaction of the factors to be stable and constant for each teacher on every occasion. Attitudinal and contextual factors may well differ from day to day, and even from class to class. Even the impact of professional factors such as explicit knowledge of grammar may vary to a certain extent, depending on the particular grammatical structure. 
Professional factors :

e.g. knowledge of subject matter

(i.e. explicit grammar knowledge);

communicative language ability; teaching experience

Attitudinal factors :
e.g. confidence +
readiness/willingness
to engage with language-
related issues

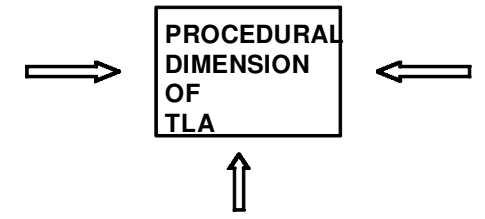

Contextual factors :

e.g. time, syllabus
Personality factors :

e.g. sensitivity,

perception,

vision, alertness,

reflectiveness

Figure 4 Key influences on the operation of TLA (Source: Andrews, 1999b: 190)

\section{Teachers' 'Engagement' with Content-related Issues}

It was suggested above that engagement is a key factor affecting the application of TLA in pedagogical practice. The rest of the paper focuses upon this specific factor. Engagement is itself susceptible to influences, including the teacher's (lack of) confidence, and the extent to which, when thinking about her teaching, she is prepared to give priority to issues of language content as against questions of methodology, classroom organisation, and student responsiveness. The potential consequences of both lack of engagement with content and of deficiencies in TLA are all too apparent from the data in Andrews (1999b), particularly in the classroom itself, but also in relation to both preparation and post-lesson reflection, when they occur. Limitations in a teacher's language awareness seem that much more likely to have a negative impact in the classroom if the teacher is insufficiently engaged with the mediation of the input made available to learners.

The following lesson illustrates the point. The teacher, Maggie, was giving a lesson on conditional sentences. During the lesson, to the amusement of her students, Maggie used as example sentences If the Principal were nice, the students would enjoy school life and If the Principal had been nice, the students would have enjoyed school life. Maggie told the class that the first situation was unlikely, and the second impossible, making no reference to time in her explanation. When asked in the post-lesson interview why the second situation was impossible, Maggie gave this fanciful (and grammatically incorrect) justification:

Well, actually what I've in mind is like this situation is impossible because of her personality. It's not about the time. I think most of the student understand that it's not about time that cannot be changed, so we slightly change the use of that. (Andrews, 1999b: 167)

The impression that Maggie conveys is that she is more concerned with the affective dimension of her teaching (engaging the interest of her students) than with content-related issues. Insufficient engagement with content, possibly rein- 
forced by a weakness in her own underlying subject-matter knowledge, causes Maggie to present students with examples and explanations which could well lead them to make incorrect generalisations.

Figure 5 (from Andrews, 1999b) derives from impressions formed after analysis of a range of qualitative data sources. It is an attempt to represent visually the relationship between engagement and awareness. The diagram is, of course, inevitably a simplification: as we have already noted, the interrelationship among the various factors mentioned earlier is very complex. However, it may help to clarify how two of these factors interact. Since engagement and awareness are both matters of degree, the individual teacher might be placed at any point on the diagram.

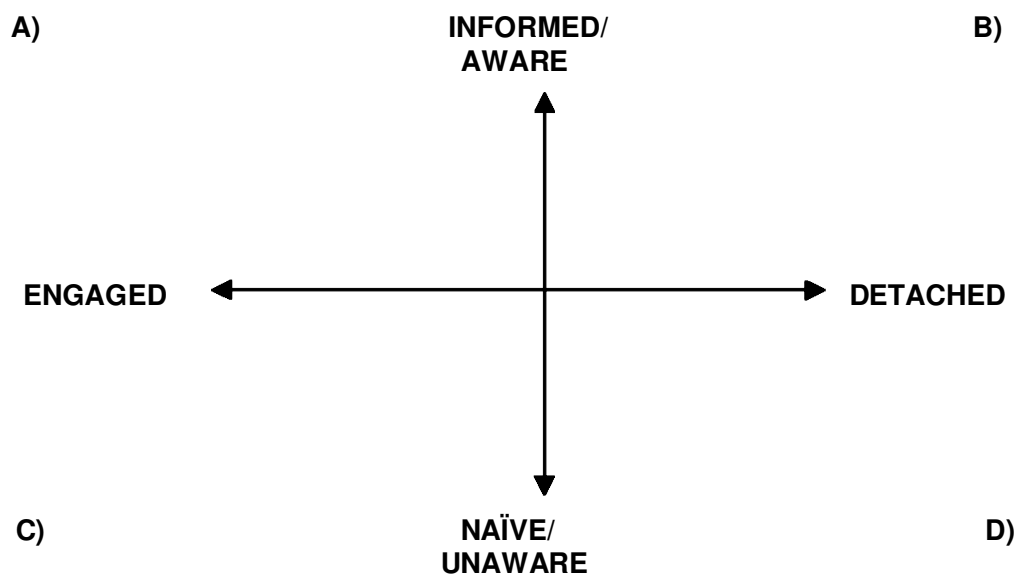

Figure 5 Styles of teacher engagement (Source: Andrews 1999b: 207)

It should be noted that the vertical continuum itself represents a simplification, since it masks the essential difference between the two dimensions of TLA, discussed earlier, between what one might label knowledge (the declarative dimension) and awareness (the procedural dimension). As the analysis in Andrews 1999b reveals, there are teachers who have knowledge, whose declarative TLA is very sound, but who lack awareness. Such teachers possess the relevant knowledge base, but they lack the ability, for example, to view language acquisition issues from the learner/learning perspective, and/or to monitor aspects of their own output. Equally, there may be teachers who have awareness, but lack knowledge. Teachers with such a profile may be capable of reflection, and of perceiving the needs and problems of students, and may be conscious of the importance of viewing what is to be taught from the learning perspective. They may nevertheless find their attempts to engage with content-related issues undermined by a lack of knowledge.

Teachers occupying the four most extreme positions shown in Figure 5 might be expected to have the following characteristics: 
- Teacher A engages with content fully, in a principled manner. She possesses a sound language systems knowledge base, is well aware of issues of language content, confident about her ability to handle them, and fully prepared to engage with them from a learner/learning perspective.

- Teacher B, by contrast, adopts a position of principled, informed detachment from content issues. Like Teacher A, she too possesses a very solid language systems knowledge base, but she espouses a set of teacher beliefs which emphasise fluency/acquisition to the virtual exclusion of any explicit focus on grammar.

- Teacher $C$ attempts to engage with issues of language content, but does so in a naïve, ill-informed way. She appreciates the need to try to engage with such issues, but lacks the knowledge base, the awareness and /or the confidence to do so effectively.

- Teacher D does not attempt to engage with issues of language content, and lacks the language systems knowledge base which might enable her to do so effectively. She may be unaware of the desirability of engaging with the language-related aspects of her teaching, or she may simply be unsure how best to engage with content.

Among the 17 teachers discussed in Andrews (1999b), there were no examples of teachers whose profiles in any way matched that of Teacher B. The majority of the teachers in that study would need, on the evidence available, to be placed in the bottom half of the diagram. However, there were examples in the data of teaching which matched the Teacher A profile, in part at least. The following three extracts from the data offer snapshots of teachers exhibiting some of the characteristics of Teachers D, C and A.

The example of Teacher $\mathrm{D}$ behaviour is taken from a semi-structured interview with a teacher called Benjamin, immediately following a grammar lesson. Preparation for the grammar lesson preceding this semi-structured interview had provided Benjamin with a strong incentive and plenty of opportunity for careful planning and thoughtful analysis of content: the lesson formed part of a grammar teaching action research project which Benjamin was carrying out as part of an in-service training programme, a project on which he would be assessed. In spite of this, however, Benjamin showed few signs of having engaged meaningfully with the language content of the lesson (conditional sentences). Contrary to the advice given in the action research project guidelines, Benjamin appeared to have given little or no serious thought to the previous learning of his Form 4 students or to the learning difficulties posed by the grammar area, as the following exchanges reveal:

Interviewer: What did you have in mind that they would already know?

Benjamin: Because I assume their level is not very good, I think I need to elaborate every steps and give more information... and probably they will have problems with passive voice. So I try to avoid assigning the exercise using passive voice.

Interviewer: So did you assume that they had already had some exposure to conditional sentences?

Benjamin: When I come to class and after 30 minutes I think they have already experienced them ... 
Interviewer: Were there any difficulties that you anticipated that they might have [with conditionals] ... from their point of view?

Benjamin: Their point of view? ... Actually I didn't think much ... I'm not try think of it. (Andrews, 1999b: 166-167)

It should be noted in passing, however, that the snapshot of Benjamin's teaching described in Andrews (1999a) accords more closely with the profile of Teacher C than with that of Teacher D. This underlines the need for caution in any generalisations about aspects of a teacher's language awareness based on a limited set of data.

The Teacher $\mathrm{C}$ snapshot comes from a lesson given by a teacher called Tony. Tony's aim in his lesson was to help his Form $3^{3}$ students: 'to learn the difference between the past perfect tense and simple past tense and to understand in what situation these two tenses are used so that they themselves can use the tenses correctly'. As Tony commented in his lesson plan: 'Learners have learnt what simple past tense and past perfect tense are, but they are confused with the difference between the two. They seldom use the tenses correctly in their writing and can hardly realise the meaning of the past perfect tense in their reading'. Tony's focus on the past simple/past perfect distinction began with a picture story: the students were required to study the text accompanying the pictures, locate/identify the verb groups, and induce the differences in the use of the two verb forms. Unfortunately, however, the text written by Tony to accompany the pictures suggests that he is as confused as his own students about the use of the past perfect. The story begins with three simple sentences containing past perfect verb groups. However, the tense selection is inappropriate in each case, since there is no past time of orientation justifying the use of past perfect rather than past simple: 'On the 7 th January 1996, a terrible accident had happened. A man and a dog had been killed by a lorry near the road. They had become ghosts! One week later, an old man drove his car near the place where the accident had taken place ...'. (Andrews, 1999b: 162). The lesson reflects a genuine attempt to engage with content, but one which is sadly undermined by inadequate subject-matter knowledge, at least of this specific area of grammar.

The illustration of the Teacher A profile which follows is also discussed in Andrews (1999a) (where the teacher was given the name Alex). It is used again on this occasion partly because it is such a clear example of Teacher A behaviour, but also because the data contain so few other such examples. In this particular case, the engagement of the teacher (now known as Yan) with the grammatical content of the lesson, and his highly developed TLA enable him, before the class, to spot what appears to be a flaw in the coursebook's handling of the grammar area under focus, a flaw which he is able to exploit to his (and his students') advantage.

Yan's lesson is focused upon the use of the present participle to join two sentences with the same subject. The first practice exercise in the coursebook requires students to:

Rewrite the sentences using the correct-ing participle. Follow the example:

(1) Peter received a call on his radio. He went straight to the scene of the robbery. 
Receiving a call on his radio, Peter went straight to the scene of the robbery. (Sampson, 1994)

The fourth item in the exercise is problematic, however, because the two sentences do not have the same subject ('The ambulance arrived a few minutes later. The man was taken to hospital'.)

Fortunately, when Yan prepared the lesson, his TLA was fully engaged, enabling him to evaluate each item against his understanding of the grammar area. As a result, he noticed the potential difficulty, and was able to transform it into an interesting learning challenge, by setting his students the task of resolving the problem. During the actual lesson, with Yan's guidance, the students were able to do this by making a change to the second sentence ('The ambulance took the man to hospital') so that they could then join the sentences in accordance with the desired pattern (Arriving a few minutes later, the ambulance took the man to hospital) (Andrews, 1999a: 174-175; 1999b: 161-162).

\section{Conclusions}

Teacher language awareness is an area of perennial concern to language teacher educators. When those concerns are expressed, TLA is often talked about as though there were a clear and shared understanding of what the term means. The view underlying the present paper is that TLA is often discussed in ways which overlook its complexity. In this paper, therefore, an attempt has been made to analyse what TLA is, and to examine its impact on pedagogical practice.

In the course of the discussion, the following key points about TLA were emphasised:

- the central importance to TLA of subject-matter knowledge (the 'declarative' dimension of TLA);

- the complex relationship between subject-matter knowledge and communicative language ability arising from the fact that in language teaching content and medium of instruction are intertwined;

- the metacognitive nature of TLA;

- the close connection with pedagogical content knowledge;

- the importance of the 'procedural' dimension of TLA.

A model of TLA was then proposed (Figure 1), taking account of these points.

The paper then went on to explore the ways in which TLA affects teacher behaviour. It was argued that the key influence of TLA is on the way in which input is made available to learners, and it was suggested (Figure 2) that TLA might usefully be thought of as a kind of 'filter', which teachers operate with varying degrees of success (see Andrews, 1999a). The final part of the paper focused explicitly on the procedural dimension of TLA, analysing its impact on pedagogical practice. It outlined the potential effects of TLA within the classroom (Figure 3), and presented an overview of the range of factors which influence the operation of TLA (Figure 4), before focusing on one of those factors in more detail: the extent to which the teacher actually 'engages' with content-related issues in her teaching (Figure 5).

As indicated in the previous section, there is a very complex interrelationship between TLA and the various factors which influence its operation. In isolating 
one factor - engagement - for study, it is important not to overlook the impact of others. Having said that, however, the interrelationship of awareness and engagement is an area which would benefit greatly from further research, perhaps by means of detailed case-studies of a small sample of teachers. The nature of teacher engagement with language-related issues, influences upon the engagement/detachment of individual teachers, variations of engagement within an individual teacher, and the impact of engagement on both the development and application of TLA, are all worthy of investigation. At the same time, it would be useful to examine other related factors, including the causes of teacher (lack of) confidence in relation to grammar, and the impact of such feelings upon pedagogical practice, including teachers' employment of avoidance strategies.

The illustrations of content-related teacher behaviour discussed above are all from a study of a group of non-native-speaking teachers of English, from a Chinese cultural background, working within a particular context: secondary schools in Hong Kong. Given that the data were collected by a native-speaking researcher, it is inevitable that both the gathering and interpretation may have been affected by differences of cultural and linguistic background. A replication study by a cultural and linguistic 'insider' would therefore make a valuable contribution to our understanding of TLA. The acknowledgement of such limitations highlights the need for further research in this area: research which would include studies of the language awareness of teachers, both NNS and NS, of a range of languages in a variety of contexts.

\section{Correspondence}

Any correspondence should be directed to Stephen Andrews, Department of Curriculum Studies, University of Hong Kong, Pokfulam Road, Hong Kong (sandrews@hkucc.hku.hk).

\section{Note}

1. Form 4 in Hong Kong secondary schools is the equivalent of Year 10 in the UK system. Students are typically 14 or 15 years old.

2. It should be noted that this argument applies specifically to situations where the L2 is taught through the L2. In contexts where the L1 is the medium of L2 instruction, TLA might be significantly different in nature.

3. Form 3 is the equivalent of UK Year 9.

\section{References}

Anderson, J. (1983) The Architecture of Cognition Cambridge, MA: Harvard University Press.

Andrews, S.J. (1994) The grammatical knowledge/awareness of native-speaker EFL teachers. In M. Bygate, A. Tonkyn and E. Williams (eds) Grammar and the Language Teacher (pp. 69-89). Hemel Hempstead: Prentice Hall.

Andrews S.J. (1997) Metalinguistic awareness and teacher explanation. Language Awareness 6 (2\&3), 147-161.

Andrews, S.J. (1999a) Why do L2 teachers need to 'Know About Language'? Teacher metalinguistic awareness and input for learning. Language and Education 13 (3), 161-177.

Andrews, S.J. (1999b) The metalinguistic awareness of Hong Kong secondary school teachers of English. Unpublished PhD thesis, University of Southampton, UK.

Bachman, L. (1990) Fundamental Considerations in Language Testing. Oxford: Oxford University Press. 
Brophy, J. (ed.) (1991) Advances in Research on Teaching, Vol. 2. Greenwich, CT: JAI Press. Brown, H.D. (2000) Principles of Language Learning and Teaching (4th edn). White Plains, NY: Addison Wesley Longman.

Ellis, R. (1990) Instructed Second Language Acquisition. Oxford: Blackwell.

Gombert, J.E. (1992) Metalinguistic Development. New York: Harvester Wheatsheaf.

Leech, G. (1994) Students' grammar - teachers' grammar - learners' grammar. In M. Bygate, A. Tonkyn and E. Williams (eds) Grammar and the Language Teacher (pp. 17-30). Hemel Hempstead: Prentice Hall.

Mitchell, R. and Myles, F. (1998) Second Language Learning Theories. London: Arnold.

Sampson, N. (1994) English 2000 Book 3. Hong Kong: MacMillan.

Schon, D.A. (1983) The Reflective Practitioner: How Professionals Think in Action. New York: Basic Books.

Shulman, L. (1986) Paradigms and research programs in the study of teaching: A contemporary perspective. In M.C. Wittrock (ed.) Handbook of Research on Teaching (3rd edn) (pp.3-36). New York: Macmillan.

Shulman, L. (1987) Knowledge and teaching: Foundations of the new reform. Harvard Educational Review 57 (1), 1-22.

Thornbury, S. (1997) About Language. Cambridge: Cambridge University Press. 